\title{
Care Needs and Caregivers: Associations and Effects of Living Arrangements on Caregiving to Older Adults in India
}

\author{
Allen Prabhaker Ugargol ${ }^{1,2}$ (D) Inge Hutter $^{3}$ • \\ K. S. James ${ }^{4} \cdot$ Ajay Bailey $^{3}$
}

Published online: 28 April 2016

(C) The Author(s) 2016. This article is published with open access at Springerlink.com

\begin{abstract}
As the ageing phenomenon continues in India, we explore the care needs of older adults and identify caregivers for specific care needs across living arrangements. Using the United Nations Population Fund (UNFPA) conducted Building Knowledge Base on Population Ageing in India (BKPAI 2011) data comprising 9850 older adults, we employed statistical methods to analyze the data, find associations and used binary logistic regression to model the adjusted and unadjusted effects of living arrangements on caregiving to older adults for specific care needs. Care-requiring situations considered were acute sickness, sickness requiring hospitalization, chronic morbidity, functional disability represented by ADL and IADL limitations, and locomotor disability. Results indicate that living arrangements of older adults were significantly associated with health, functional status and disability as well as caregiving patterns. Our results suggest that co-residence with children and all others was beneficial to older adults in obtaining care from a family caregiver for their hospitalization and chronic morbidity needs while living with spouse or living with a
\end{abstract}

Allen Prabhaker Ugargol

a.p.ugargol@rug.nl; allen@isec.ac.in

Inge Hutter

i.hutter@rug.nl

K. S. James

james@isec.ac.in

Ajay Bailey

a.bailey@rug.nl

University of Groningen (RUG), Groningen, The Netherlands

2 Institute for Social and Economic Change (ISEC), Bangalore, India

3 Faculty of Spatial Sciences, University of Groningen, Groningen, The Netherlands

4 Population Research Centre (PRC), Institute for Social and Economic Change (ISEC), Bangalore, India 
partner was advantageous for older adults in receiving care for their ADL limitations and during hospitalizations. Mean number of children was also significantly associated with the availability of a caregiver during hospitalization, locomotor disability, chronic morbidity and acute sickness. The study also highlights a little known phenomenon, that there was familial help available to older adults who lived alone. Notably, non-family sources of caregiving were steadily becoming visible (as high as 8-10\% of the caregiving component) especially among older adults living alone.

Keywords Ageing · Caregiving · Care needs · Caregiver · Older adults · Living arrangements $\cdot$ India

\section{Introduction}

As India experiences the demographic transition, older individuals are now living longer with increasing life expectancy, and at the same time, are also requiring more assistance or care to manage their day to day activities. As substantially large cohorts are now surviving to older ages in India, there is an increased need for elder care and support. In India, as in most Asian countries, the family is a cherished social institution, and co-residence has been the traditional way by which families met the care needs of their older adults. Studies have reinforced that home-based care with family members as primary caregivers was still the first and often the only option for a majority of older adults, and the most common type of living arrangement in India was found to be living with married sons and their families (Devi and Indira 2007; Prakash 1999). Unfortunately, demographic shifts are reducing the availability of familial support to India's older adults (Krishnaswamy et al. 2008; Rajan and Kumar 2003). Alongside the increase in population of older adults, there is a simultaneous decline in the number of younger family members available to care for these older adults due to several reasons. There has so far been limited evidence available on older adults' living arrangements and caregiving patterns for their health and functional needs. Studies on living arrangements of Indian older adults have focussed on their health and functional status for long but have not explored the caregiver type and caregiving patterns for different requirements, limitations and disabilities of older adults (Devi and Indira 2007; Prakash 1999; Sudha et al. 2006; Agarwal 2012). This study aims to explore the care needs of older adults, identify caregivers to older adults for their health and functional needs, and investigate differences in caregiving to older adults' by their living arrangements. With India's older adult population currently at $8.57 \%$ of their total population (Census of India 2011), information on living arrangements and caregiving patterns to older adults for their health, functional and disability needs will be pertinent to generate knowledge for debate, policy and action.

In ageing literature, living arrangements have either been defined by household composition or by the number and identity of the cohabitants. Across the world, families have always been considered the mainstay in terms of caregiving to older adults. Even in the United States nearly two-thirds of the 5.5 million older adults with chronic disabilities rely, often exclusively, on family members for help with basic activities of daily living (Spillman and Pezzin 2000). Co-residence has been recognised as an important mode of support that adult children provide for their elderly parents. 
While a quarter to half of older adults in the developed world might have adult children co-residing, co-residence of older parents and adult children ranges from two-thirds to three-quarters across Asia, Africa and Latin America (United Nations 2005). Family roles involve expectations and obligations that shift over the course of life and living arrangements have been closely connected with co-residence status, living with/without a partner and marital status in much of published literature. There is also evidence of a close relation between health and well-being of older adults and their living arrangements (Sereny 2011; Agarwal 2012); however, there is no information on who dons the caregiving role in such a scenario. In a patriarchal society, where gender roles dominate and where women do most of the housework and caregiving, co-residence with one's spouse may be more beneficial for men since women handle the caregiving role. Interestingly, Indian women have also benefitted from the presence of the spouse and sons in the household, owing mainly to their general dependence on significant others and the socio-cultural security of having a surviving spouse (Lamb 1999).

A complex familial exchange of care ensues between parents and children and also among the extended family and social networks of the elderly in many Asian cultures including India (Agree et al. 1999). Traditional multi-generational households have historically represented an intricate social network system that ensured care for older adults from within the family or within their extended social network. Unfortunately, traditional family-based care is becoming less common than in the past in India (Arokiasamy et al. 2010) due to the following reasons. Firstly, fertility reductions led to fewer children being available to care for older family members and secondly, with increased education, migration for employment and better economic opportunities, movement of adult children away from the traditional household has become inevitable leaving behind older dependents (Visaria 1999; Deshingkar and Akter 2009). While it becomes imperative to explore how the institutions of family and healthcare adapt and cope with the demographic and health transition that challenge the care of the elderly (Lee 2003; Lloyd-Sherlock 2010), very little evidence exists from India on the form and extent of care received by the elderly in the changing scenario. Increased requirement of care is also not free from financial burden; however, in the Indian context, receiving paid or formal care may not be feasible or culturally appropriate for most of the older adult population. Even with regard to opting for formal care such as in times of medical need, the decision to go in for formal care is taken by family and extended family (Levkoff et al. 1999) who often remain primary caregivers. Very few studies in India have looked at care requirements of older adults and their sources of care and support, however, these have been very localized in nature (Panigrahi 2009; Sudha et al. 2006). Studies thus far on older adults' health status and caregiving patterns in India have been fragmented and although there is some evidence on the association between older adults' living arrangement patterns and their health status, there is paucity of information on caregiving patterns to older adults by their living arrangements and for specific care needs.

\section{Understanding Social Change and Familial Support for Older Adults in India}

Historically, India does not have a well-developed social security system since a majority of the workforce belongs to the informal sector. Hence, work related pension is available only to around $10 \%$ of the Indian population who had been part of the formal workforce. In the absence of a formal social support programme in India, older individuals 
tend to depend on filial piety and intergenerational support during their old age (Gupta and Pillai 2002) for financial as well as other forms of support. A strong tradition of filial piety is visible in India and is expressed through co-residence of older adults with their adult children. This co-residence is known to facilitate support systems between the elderly and their adult children (Chan 1997; Knodel and Chayavon 1997). However, the flow of support is not unidirectional from the adult child to the older parent but rather of a reciprocal nature. Studies have also shown that there are benefits to older adults' health on account of co-residence, particularly in terms of the relationship between co-residence and self-rated health, chronic and short-term morbidity (Sudha et al. 2006; Agarwal 2012).

Recently, living alone has been on the rise in India. In the absence of a financial safety net for older adults living alone, this adds a new potential poverty dimension to ageing in India (Husain and Ghosh 2011). The NSSO data (60th Round) conducted in 2004 showed that $5.2 \%$ of India's older adults lived alone and another $12 \%$ of them lived with their spouse exclusively. The main reasons for living alone were reported as widowhood, not having children or children living elsewhere on account of migration. The recent BKPAI Report (2011) finds that $6 \%$ of India's older adults live alone and $15 \%$ of them live with their spouses exclusively. We see a gradual trend towards increasing numbers of older adults living alone bereft of their family and gender plays a role too. The Situation Analysis of the Elderly in India (2011), highlighted that nearly $50 \%$ of Indian older adults are dependents, often due to widowhood, divorce, or separation, and a majority of these elderly individuals are women $(70 \%)$ and 1 out of 10 elderly women lives alone. In the southern State of Tamil Nadu for example, it was observed that as high as $16.2 \%$ of women lived alone (Report on the Status of Elderly in Select States of India 2011).

\section{Health, Functional and Disability Needs of Older Adults in India}

With modernization, older adults increasingly face barriers to good health status and 'care' from within the family on account of family nuclearization and increase in dependency (Gupta and Sankar 2002; Rajan and Prasad 2008). Ill health and disability are known to have a significant impact on economic security, level of independence and social interaction of the elderly too (Bloom et al. 2010). In the recent past, the prevalence of chronic disease among the elderly in India has been showing a steady increase (Situation Analysis of the Elderly in India 2011), particularly cardiovascular, metabolic, and degenerative disorders (Ingle and Nath 2008). Chronic morbidity necessitates constant care and support for older adults; however, with declines in family support, it is pertinent to explore how their care needs are being addressed.

Disability is generally considered a good indicator of overall health status among older populations as it is thought to be the result of cumulative damage created by the chronic disease processes that affect humans throughout life and that manifest themselves in older ages (Fried and Guralnik 1997; Pope and Tarlov 1991). Several theoretical measures have been put forth to explain different levels of physical disability (World Health Organization. WHO 1980; World Health Organization WHO 2002). A very large majority of older adults suffer from diminished functional abilities in physical (eating, bathing, dressing, walking, climbing stairs, getting-up from a sitting position, etc.) as well as sensory (hearing and vision) health domains (Alam 2006). Everyday 
self-maintenance activities (ADL and IADL) are considered prominent indicators of disability which require assistance (Albert 2004). Impairment in everyday activities indicates cognitive and motor deficits to carry out work-a-day routine tasks. Health and well-being of older adults are thus affected by interwoven aspects of their social and physical environment and family support has been found to be an important factor affecting the health and ability of older adults in managing their daily activities (Devi and Murugesan 2006).

\section{Objectives}

The specific objectives of this study are to investigate the association between living arrangements and the health and functional status of older adults in India, to explore differentials by living arrangements on caregiving patterns to older adults for their health and functional needs and to assess the effect of living arrangements on caregiving patterns to older adults. In particular, we aimed to answer the following questions, namely, are there differentials in older adults' health and functional status by living arrangements?, are there variations in caregiving to older adults' health and functional needs by their living arrangements?, and what is the effect of living arrangements on caregiving patterns and do other socio-demographic, family support and socioeconomic factors mediate the association?

The paper explores the health and functional needs, care gaps and identifies caregiving patterns to older adults by their living arrangements. By care needs, the special situations in which older adults require assistance such as during times of sickness, functional limitations and disability are considered. Care gaps refer to situations where older adults have to self-assist themselves as significant others who could offer them assistance are either not living with them or due to other reasons are unable to assist them. Caregiver types being explored here include: Self, Spouse, Family Caregiver and Non-Family Caregiver. It is hypothesised that older adults living with spouse, children and/or in family settings would obtain informal care from family caregivers in contrast to older adults who live alone, are without a spouse and who live away from their children. The latter group of older adults is hypothesized to have considerably reduced access to family-based informal care and could be depending more on relatives and non-family caregiving sources such as neighbours, friends, extended social support networks including community and religious institutions apart from formal care.

\section{Research Design}

The data for the study were drawn from a cross-sectional survey of older adults in India conducted by the United Nations Population Fund (UNFPA) under a larger study on 'Building Knowledge Base on Population Ageing in India' (Report on the Status of Elderly in Select States of India 2011). The sample consisted of 9850 (N) older adult respondents aged 60 years and above from seven states across India which included Odisha, West Bengal, Maharashtra, Himachal Pradesh, Punjab, Tamil Nadu and Kerala. In each of these Indian States, the proportion of older adults was higher than the national average. 


\section{Variables}

Living Arrangements: Living arrangement is the predictor variable in this study and is constructed based on the information about household members living in the household. Living arrangement was categorised into: 'living alone', 'living with spouse' and 'living with family'. 'Living alone' meant that the older adults were living without the spouse and other kin. 'Living with spouse' meant the older adults lived exclusively with their spouse and 'Living with family' meant that the older adult lives with spouse (if available), children, son-in-law, daughter-in-law and grandchildren as available.

Socio-Demographic: Variables included are gender, age group, place of residence, marital status and children. Marital status was coded into currently married/living together and currently single (included widowed, separated, deserted and divorced individuals). The mean number of children was included.

General Health: Self-rated health is one of the variables under health characteristics. Respondents had been asked to rate their general health status on a scale of excellent, very good, good, fair and poor. Excellent and very good were grouped together. Good and fair were clubbed into the second category and 'poor' health was retained as such.

Acute Sickness: Acute Sickness was measured in response to the question 'were you sick for any time during the last 15 days without requiring hospitalization'. Positive responses were categorised as 1 (any ailment) and negative responses into 2 (no ailment).

Hospitalization: Particulars of medical treatment received as an inpatient during the past 12 months were measured in response to the question 'Did you have any major health problem during the last 365 days requiring hospitalization? Positive responses were coded into 1 (any hospitalization) and negative responses into 2 (no hospitalization).

Chronic Morbidity: Chronic Morbidity was measured in response to the question 'has any doctor or nurse ever told you that you have any of the following ailments?'. The list of chronic ailments comprised of 20 chronic diseases (stroke, heart disease, diabetes, cancer, etc.). Positive responses were coded into 1 (any chronic morbidity) and negative responses into 2 (no chronic morbidity).

Functional Limitations: Respondents were asked to self-report whether they had any difficulty with activities of daily living (ADL) and Instrumental Activities of Daily Living (IADL). The ADL measure consisted of 6 tasks, including bathing, dressing, toileting, mobility, continence and feeding. Responses were coded based on the presence or absence of difficulty into 'any ADL limitations' and 'no ADL limitations'. The IADL scale consisted of eight tasks: using the telephone, daily shopping, preparing meals, doing housekeeping, doing laundry, transportation, taking medications and handling personal finances. Similar to ADL limitations, responses for IADL limitations were coded into 'no IADL limitations' and 'any IADL limitations'. The sum score for IADL reflected functional status with lower scores indicating more intact functional abilities. Mean ADL and mean IADL were also computed. 
Locomotor Disability: Respondents were asked if they had difficulty with respect to vision, hearing, walking and chewing. Positive responses (those requiring partial and full assistance) were coded as 'any one disability' and negative responses into 'no disability'.

Socio-Economic Characteristics: Socio-economic measures included the wealth index, financial status of older adults in the household and financial dependency. The wealth index, an indicator of economic status of households, is consistent with expenditure and incomes measures (Rutstein 1999). This index was constructed using information on household assets and housing characteristics. The financial status of older adults was measured with the response categories being 'not dependent', 'partially dependent' and 'fully dependent). Whether the older adult contributed to the household expenditure was also ascertained and 'whom the older adult depends on for financial support to meet basic needs' was recorded with the response options being Spouse, Any Family, Other relatives/friends, NGO, community, etc.

Caregiver Characteristics: Responses of older adults to questions that ranged from assistance provided for functional assistance in ADL and IADL tasks, chronic morbidity management, acute illness, morbidity including hospitalization, and locomotor disability concerns of older adults were included: who provides assistance for ADL tasks (main caregiver)?, who pays for the treatment expenditures in case of chronic morbidity?, who paid for their acute sickness (outpatient) treatment expenses?, who stayed with the older adults to provide care in the hospital? And who provided aids to older adults to overcome their locomotor disability? The study categorised caregivers into - 'family caregiver' (son, daughter, daughter-in-law, son-in-law, unmarried children and grandchildren living in the same household), 'non-family caregiver' (any relative or friend), 'spouse' and 'no one'. Any 'relative' category includes sibling, cousin, aunt, uncle, niece, nephew living in a separate household while the 'friend' category includes friends, neighbours, confidants, co-workers, etc. Since responses to chronic morbidity and ADL limitations were for more than one condition, individual counts were added and caregivers by type for each condition/limitation were totaled to arrive at a cumulative caregiving proportion to older adults. In case of locomotor disabilities, the caregivers who helped older adults' procure 'aids' to overcome the respective disability were taken into account.

Care Needs: The need for care among older adults was established using health, functional limitation and disability conditions which necessitated caregiving to older adults such as the presence of an acute morbidity (sickness) event in the past 15 days, presence of chronic morbidity, sickness requiring hospitalization (any type of sickness that ended up in hospitalization included), functional status measured through the ability to perform ADL and IADL tasks with caregiver assistance and the presence of locomotor disability which necessitated the procurement of aids to overcome the disability.

Statistical Analysis: Descriptive statistics were used to present the distribution of socio-demographic characteristics, socio-economic characteristics, financial status in household and health characteristics by older adults' living 
arrangements. Chi square tests were employed to identify group differences in proportions and one-way ANOVA F-tests for continuous variables. These tests were used to identify group differences in health, locomotor and functional needs by living arrangements as well as to identify associations and differences in caregiving patterns. The dependent variables were dichotomised and binary logistic regression was employed to view the adjusted effects of living arrangements on caregiving to older adults. Results are presented in the form of odds ratio (ORs) with 95\% CI (confidence intervals). The estimation of confidence intervals takes into account design effects. In order to maintain representativeness of the sample and avoid oversampling of certain categories among variables, appropriate weights have been used. A $p \leq 0.001$ was considered statistically significant. The data were analysed using the Statistical Package for the Social Sciences SPSS Inc. Released 2009. PASW Statistics for Windows, Version 18.0. Chicago: SPSS Inc.

\section{Results}

The descriptive characteristics (Socio-Demographic, Health, Socio-Economic and Financial status in Household) of the study sample by Living Arrangements are depicted in Table 1. The 9850 respondents were classified based on their living arrangements into 3 categories: older adults living alone/living with servant (6.2\%), those living with spouse/living with spouse and servant (14.9\%) and those older adults living with children and others $(78.9 \%)$ respectively. The proportion of older adult women who lived alone was nearly four times in comparison to older adult men. Significantly, nearly twice the number of older adult men lived with their spouses as compared to women older adults. A higher proportion of older adults living alone and living with spouse exclusively were from the lowest quintile of the wealth index. A higher proportion of older adults living with spouse and those living alone were financially independent while a higher proportion of older adults who lived alone and those who lived with spouse were dependent on any family member for financial needs.

Table 2 represents the distribution and differences in health and functional status by living arrangements of older adults. A higher proportion of older adults living with spouse rated their general health status as excellent/very good compared to the rest. A higher proportion of older adults who lived alone and those who lived with children and all others had suffered from an acute sickness episode in the past 15 days as compared to older adults who lived with their spouse/partner. A higher proportion of older adults who lived with children and others had suffered from a hospitalization in the past 1 year, suffered from the presence of any chronic morbidity, reported of any locomotor disability (vision, hearing, walking, chewing, speaking and memory) and had higher ADL limitations as compared to older adults living with spouse/partner and those living alone. Older adults living with children and others also had higher mean ADL limitations score $(2.87 \pm 1.83)$ as compared to older adults living with spouse/ partner $(2.50 \pm 1.76)$ and older adults living alone $(1.75 \pm 1.63)$. Only with respect to IADL limitations did older adults living with children and others have better outcomes. 
Table 1 Description of the study sample (socio-demographic, health and socio-economic characteristics of older adults) by their living arrangements $(N=9850)$

\begin{tabular}{|c|c|c|c|c|c|}
\hline & $\begin{array}{l}\text { Living alone } \\
(n=612 ; 6.2 \%)\end{array}$ & $\begin{array}{l}\text { Living with } \\
\text { spouse only } \\
(n=1468 ; \\
14.9 \%)\end{array}$ & $\begin{array}{l}\text { Living with } \\
\text { children } \\
\text { and/or others } \\
(n=7770 ; \\
78.9 \%)\end{array}$ & $\begin{array}{l}\text { Total } \\
N=9850\end{array}$ & $p$-value \\
\hline \multicolumn{6}{|c|}{ Socio-demographic characteristics } \\
\hline \multicolumn{6}{|l|}{ Gender } \\
\hline Men & 2.5 & 20.1 & 77.4 & 4672 & \multirow[t]{2}{*}{$<0.001$} \\
\hline Women & 9.6 & 10.2 & 80.2 & 5178 & \\
\hline \multicolumn{6}{|l|}{ Residence } \\
\hline Rural & 6.5 & 17.3 & 76.0 & 5137 & \multirow[t]{2}{*}{$<0.001$} \\
\hline Urban & 5.8 & 12.2 & 81.9 & 4713 & \\
\hline \multicolumn{6}{|l|}{ Age group } \\
\hline $60-69$ years & 6.0 & 15.7 & 78.3 & 6238 & \multirow[t]{3}{*}{$<0.001$} \\
\hline 70-79 years & 6.9 & 15.2 & 78.0 & 2600 & \\
\hline $80+$ years & 5.9 & 9.4 & 84.7 & 1012 & \\
\hline \multicolumn{6}{|l|}{ Marital status } \\
\hline $\begin{array}{l}\text { Currently married/ } \\
\text { living together }\end{array}$ & 0.7 & 24.8 & 74.5 & 5885 & \multirow[t]{2}{*}{$<0.001$} \\
\hline Currently single & 14.4 & 0.3 & 85.4 & 3965 & \\
\hline \multicolumn{6}{|l|}{ Children } \\
\hline $\begin{array}{l}\text { Mean number } \\
\text { of children } \\
(\text { Mean } \pm \text { SD) }\end{array}$ & $2.71 \pm 1.83$ & $3.02 \pm 1.67$ & $3.46 \pm 1.80$ & $3.35 \pm 1.80$ & \\
\hline $\begin{array}{l}\text { Mean number } \\
\text { of sons } \\
(\text { Mean } \pm \mathrm{SD})\end{array}$ & $1.30 \pm 1.27$ & $1.44 \pm 1.22$ & $1.87 \pm 1.16$ & $1.78 \pm 1.19$ & \\
\hline $\begin{array}{l}\text { Mean number } \\
\text { of daughters } \\
(\text { Mean } \pm \text { SD) }\end{array}$ & $1.42 \pm 1.23$ & $1.58 \pm 1.23$ & $1.59 \pm 1.34$ & $1.58 \pm 1.32$ & \\
\hline \multicolumn{6}{|c|}{ Socio-economic characteristics } \\
\hline Wealth index $(n=9844)$ & & & & & \multirow[t]{6}{*}{$<0.001$} \\
\hline Lowest quintile (Q1) & 15.5 & 22.7 & 61.8 & 1954 & \\
\hline Second quintile (Q2) & 7.3 & 16.1 & 76.5 & 1974 & \\
\hline Middle quintile (Q3) & 5.0 & 13.6 & 81.4 & 1938 & \\
\hline Fourth quintile (Q4) & 1.8 & 11.0 & 87.2 & 1961 & \\
\hline Highest quintile (Q5) & 1.6 & 11.2 & 87.2 & 2017 & \\
\hline \multicolumn{6}{|l|}{ Financial status in household } \\
\hline Not dependent & 11.7 & 24.7 & 63.5 & 2488 & \multirow[t]{3}{*}{$<0.001$} \\
\hline Partially dependent & 4.8 & 12.1 & 83.2 & 2431 & \\
\hline Fully dependent & 7.9 & 10.6 & 81.5 & 659 & \\
\hline \multicolumn{6}{|c|}{ Financial dependence on $(n=4993)$} \\
\hline Spouse & 0.01 & 29.4 & 69.6 & 2241 & \multirow[t]{3}{*}{$<0.001$} \\
\hline Any Family & 16.8 & 34.5 & 48.5 & 1912 & \\
\hline $\begin{array}{l}\text { Other relatives/friends/ } \\
\text { NGO, community, } \\
\text { etc. }\end{array}$ & 0.2 & 14.2 & 65.7 & 840 & \\
\hline
\end{tabular}

$p$-value is from chi square tests for categorical variables 
Table 2 Distribution and differences in health and functional status by living arrangements

\begin{tabular}{|c|c|c|c|c|c|}
\hline & $\begin{array}{l}\text { Living alone } \\
(n=612 ; \\
6.2 \%)\end{array}$ & $\begin{array}{l}\text { Living with } \\
\text { Spouse Only } \\
(n=1468 ; \\
14.9 \%)\end{array}$ & $\begin{array}{l}\text { Living with } \\
\text { spouse, children } \\
\text { and others } \\
(n=7770 \text {; } \\
78.9 \%)\end{array}$ & Total & $p$-value \\
\hline \multicolumn{6}{|c|}{ Health and functional characteristics } \\
\hline \multicolumn{6}{|c|}{ General health status $(n=9830)$} \\
\hline Excellent/Very Good & 3.6 & 16.3 & 80.1 & 1604 & \multirow[t]{3}{*}{$<0.001$} \\
\hline Good/Fair & 6.7 & 15.5 & 77.7 & 6538 & \\
\hline Poor & 6.6 & 11.3 & 82.1 & 1688 & \\
\hline \multicolumn{6}{|c|}{ Acute sickness score $(n=1227)$} \\
\hline No ailment & 6.2 & 15.2 & 78.6 & 8621 & \\
\hline Any ailment & 6.6 & 12.7 & 80.7 & 1227 & \\
\hline \multicolumn{6}{|c|}{ Hospitalization score $(n=923)$} \\
\hline No hospitalization & 6.3 & 14.9 & 78.7 & 8921 & \multirow[t]{2}{*}{0.947} \\
\hline Any hospitalization & 5.4 & 14.2 & 80.4 & 929 & \\
\hline \multicolumn{6}{|c|}{ Chronic morbidity $(n=9850)$} \\
\hline No chronic morbidity & 6.8 & 17.7 & 75.5 & 3494 & \multirow[t]{2}{*}{$<0.001$} \\
\hline $\begin{array}{l}\text { Any chronic } \\
\text { morbidity }\end{array}$ & 5.9 & 13.4 & 80.7 & 6356 & \\
\hline \multicolumn{6}{|c|}{ Locomotor disability score $(n=9850)$} \\
\hline No disability & 6.7 & 19.3 & 74.0 & 2970 & \multirow[t]{2}{*}{$<0.001$} \\
\hline Any one disability & 6.0 & 13.0 & 81.0 & 6880 & \\
\hline \multicolumn{6}{|l|}{ ADL limitations } \\
\hline No ADL limitations & 6.3 & 15.5 & 78.2 & 9112 & \multirow[t]{2}{*}{$<0.001$} \\
\hline Any ADL limitation & 4.5 & 7.9 & 87.7 & 738 & \\
\hline $\begin{array}{l}\text { Mean ADL } \\
\text { limitations score } \\
(\text { Mean } \pm \text { SD })\end{array}$ & $\begin{array}{l}33 \\
(1.75 \pm 1.63)\end{array}$ & $\begin{array}{l}58 \\
(2.50 \pm 1.76)\end{array}$ & $\begin{array}{l}647 \\
(2.87 \pm 1.83)\end{array}$ & $\begin{array}{l}738 \\
(2.79 \pm 1.83)\end{array}$ & $<0.001$ \\
\hline \multicolumn{6}{|l|}{ IADL limitations } \\
\hline No IADL limitations & 0 & 1 & 0 & 1 & \multirow[t]{2}{*}{$<0.001$} \\
\hline Any IADL limitations & 612 & 1467 & 7770 & 9849 & \\
\hline $\begin{array}{l}\text { Mean IADL } \\
\text { limitations score } \\
(\text { Mean } \pm \text { SD) }\end{array}$ & $5.97 \pm 2.05$ & $5.60 \pm 1.84$ & $4.78 \pm 2.30$ & $4.97 \pm 2.26$ & $<0.001$ \\
\hline
\end{tabular}

$p$-value is from chi square tests for categorical variables and one-way ANOVA $F$-tests for continuous variables

Caregiving can be very diverse in nature with the commonly noticed tangible acts being instrumental caregiving and financial support. The distribution and differences in caregiving (instrumental) to older adults for hospitalization and ADL limitations by living arrangements are presented in Table 3. During older adults' hospitalization episode, caregivers who stayed with the older adult in the hospital were considered. In case of ADL limitations, instrumental assistance in dealing with ADL limitations was considered. Among older adults living alone, a higher proportion of them had no one to support them during times of hospitalization. A higher proportion of older adults living with spouse/partner obtained care from their spouse and older adults living with 
Table 3 Distribution and differences in caregiving by living arrangement and type of health and functional needs

\begin{tabular}{|c|c|c|c|c|}
\hline $\begin{array}{l}\text { Living alone } \\
(n=612 ; 6.2 \%)\end{array}$ & $\begin{array}{l}\text { Living with spouse } \\
(n=1468 ; 14.9 \%)\end{array}$ & $\begin{array}{l}\text { Living with spouse, } \\
\text { children and others } \\
(n=7770 ; 78.9 \%)\end{array}$ & Total & $p$-value \\
\hline
\end{tabular}

Caregivers

Caregiver during hospitalization (who stayed with older adult; $n=929$ )

$\begin{array}{lrrrrr}\text { No One (self) } & 27.0 & 18.9 & 54.1 & 37 & <0.001 \\ \text { Spouse } & 0.7 & 26.0 & 73.3 & 277 & \\ \text { Family } & 6.8 & 7.7 & 85.4 & 542 & 73 \\ \text { Non-Family } & 1.4 & 15.1 & 83.6 & & \\ \text { Main caregiver for ADL limitations }(n=719) & 30.7 & 68.7 & 150 & <0.001 \\ \text { Spouse } & 0.7 & 1.8 & 95.4 & 505 & \\ \text { Family } & 2.8 & 4.7 & 75.0 & 64 & \end{array}$

All $p$ values are chi-square $p$ values

children were most commonly cared for by the family. For ADL limitations, the spouse was the commonest caregiver for older adults living with spouse while the family cared for a higher proportion of older adults living with children and others. Older adults living alone had very little spousal and family contribution for ADL tasks and a higher proportion of them also received care from non-family sources.

Next, we looked at caregiving through financially supporting older adults for their treatment expenses. Table 4 presents the distribution and differences by caregivers who paid for treatment needs of older adults. For acute sickness, non-family contribution towards the medical expenses of older adults living alone was high followed by selffinanced care. In case of older adults living with spouse, spousal contribution was highest in proportion followed by self-financed care. For older adults living with children and others, the family was the primary support financially. Chronic morbidity expenses of older adults who lived alone were mainly handled by non-family sources of caregiving. The primary caregiver for older adults living with spouse was the spouse and it was the family which majorly supported the chronic morbidity expenses of older adults living with children and others. For provision of aids to overcome locomotor disability, older adults who lived alone were mainly supported by voluntary agents and others while older adults living with spouse were financially supported mainly by others. Children were the main financial support for older adults who lived with children and others.

Table 5 presents the unadjusted and adjusted ORs for caregiver being 'none' as against the caregiver being 'any family or non-family member' by the socio-demographic, socio-economic, and health characteristics of older adults using logistic regression models. The unadjusted ORs provide the effect of living arrangements on caregiving to older adults for hospitalization, locomotor disability, ADL limitations, chronic morbidity and acute sickness. The act of caregiving for hospitalization (who stayed with them during hospitalization) and caregiving for ADL refers to instrumental 
Table 4 Distribution and differences in caregivers who paid for the treatment needs of older adults by living arrangements

$\begin{array}{lll}\begin{array}{l}\text { Living alone } \\ (n=612 ; 6.2 \%)\end{array} & \begin{array}{l}\text { Living with spouse } \\ (n=1468 ; 14.9 \%)\end{array} & \begin{array}{l}\text { Living with spouse, } \\ \text { children and others } \\ (n=7770 ; 78.9 \%)\end{array}\end{array} \quad$ Total $p$-value

Health characteristics

Caregiver for acute sickness (who paid) $(n=955)$

\begin{tabular}{|c|c|c|c|c|c|}
\hline No one (self) & 7.7 & 16.1 & 76.2 & 311 & $<0.001$ \\
\hline Spouse & 6.3 & 33.6 & 60.2 & 128 & \\
\hline Family & 4.6 & 5.7 & 89.8 & 459 & \\
\hline Non-Family & 17.5 & 7.0 & 75.4 & 57 & \\
\hline \multicolumn{6}{|c|}{ Caregiver for chronic morbidity $(n=4966)$} \\
\hline No one (self) & 8.7 & 20.8 & 70.6 & 1848 & \multirow[t]{4}{*}{$<0.001$} \\
\hline Spouse & 2.0 & 28.7 & 69.4 & 356 & \\
\hline Family & 2.7 & 6.2 & 91.1 & 2513 & \\
\hline Non-Family & 12.0 & 6.8 & 81.1 & 249 & \\
\hline \multicolumn{6}{|c|}{ Caregiver for locomotor disability $(n=3547)$} \\
\hline No one (self) & 6.3 & 15.9 & 77.8 & 2076 & \multirow[t]{4}{*}{$<0.001$} \\
\hline Children & 2.8 & 3.4 & 93.8 & 1204 & \\
\hline Voluntary Agents & 8.5 & 8.5 & 83.1 & 59 & \\
\hline Others & 6.7 & 28.8 & 64.5 & 208 & \\
\hline
\end{tabular}

All $p$ values are chi-square $p$ values

caregiving. For acute sickness, chronic morbidity and locomotor disability, the caregiving act refers to financially supporting older adults. For ADL limitations, the contribution of self (no one) caregiving was not available in the dataset; hence, the contribution of spouse versus all others has been explored in the logistic regression (not shown in table). The adjusted model includes all other independent variables.

\section{Effects of Living Arrangements on Caregiving to Older Adults for Their Care Needs}

Considering caregivers for hospitalization, the unadjusted model shows that older adults living with spouse were more than 3 times likely to obtain care from 'any family or non-family caregiver' (OR 3.785; CI 1.07-14.42) and those older adults living with children and all others were more than 8 times more likely to receive support from 'any caregiver' (OR 8.723; CI 2.94-25.88) as compared to older adults living alone (reference category). This has remained significant in the adjusted model. In case of caregivers for locomotor disability, older adults living with spouse were less likely to obtain care from 'any caregiver' (OR 0.487; 0.28-0.87) as compared to the other categories. In the adjusted model, this likelihood altered with older adults living with spouse being more likely to receive care from 'any caregiver' (aOR 1.605; CI 0.82-3.13) and older adults living with children and all others 2.6 times more likely to receive care from 'any caregiver' (aOR 2.606; 1.54 4.41) as compared to reference category. For ADL 
limitations (not shown in table), the unadjusted model showed that older adults living with spouse were more likely to receive care from the spouse (OR 15.267; CI 3.47-67.13). For chronic morbidity needs, the unadjusted model showed that older adults living with spouse were less likely to receive care from 'any caregiver' (OR 0.988; CI 0.64-1.52) while older adults living with children and others were nearly three times more likely to receive care from 'any caregiver' (OR 2.884; CI 1.99-4.19). In the adjusted model controlling for other variables, older adults living with spouse were 2 times more likely to obtain care from any caregiver (aOR 2.166; CI 1.31-3.57) while older adults living with children and others were more than 4 times more likely to receive care from any caregiver (aOR 4.614; CI 3.01-7.07) as compared to reference category. Considering caregiver for acute sickness (not shown in table), the adjusted model showed that older adults living with spouse were nearly 1.5 times more likely to be cared for by any caregiver (OR 1.456; CI 0.57-3.73) while older adults living with children and others were 1.3 times more likely to be cared for by any caregiver for their acute sickness needs (OR 1.305; 0.59-2.87) as compared to reference category.

\section{Effect of Control Variables on Caregiving to Older Adults During Care Needs}

The discussion of the adjusted effects of the control variables focuses on all the 5 adjusted models in Table 5. With other variables controlled for, wealth index had a significant positive effect on any caregiver being available to care for the older adult during hospitalization. Gender-wise, being a woman had a significant positive effect on having any caregiver for hospitalization (OR 5.838; CI 1.34-25.48), locomotor disability (OR 3.490; CI 2.58-4.73), chronic morbidity (OR 2.801; CI 2.22-3.53) and acute sickness (OR 1.377; CI 0.82-2.31). By place of residence, urban older adults had more likelihood of obtaining care from any caregiver in case of ADL limitations (not shown in table) (OR 1.621; CI 0.50-5.24) and acute sickness (not shown in table) (OR 1.029; CI 0.67-1.57). For older adults, advanced age ( $80+$ years) had a significant and positive likelihood on a caregiver being available to care for older adults in case of locomotor disability (OR 2.215; CI 1.52-3.22), ADL limitations (OR 3.646; CI 1.01-13.13), chronic morbidity (OR 2.553; CI 1.87-3.48) and acute sickness (OR 1.042; CI 0.54-2.02). Being married/living together had a significant and positive likelihood of a caregiver being available to care for older adults in case of hospitalization (OR 3.484; CI 0.74-16.37) and ADL limitations (OR 10.599; CI 1.28-87.86). With respect to children being available, mean number of children had a significant and positive likelihood on a caregiver being available to care for older adults in case of hospitalization, locomotor disability, chronic morbidity and acute sickness. Considering financial status in the household, older adults who were partially or fully financially dependent on the household were more likely to have a caregiver to care for them in case of locomotor disability, ADL limitations, chronic morbidity and acute sickness.

\section{Discussion}

This study has utilised data from a large representative sample for older adults in India. While describing the characteristics of older adults in India as represented by their gender, age group, place of residence, marital status, living arrangements, and socio-economic 


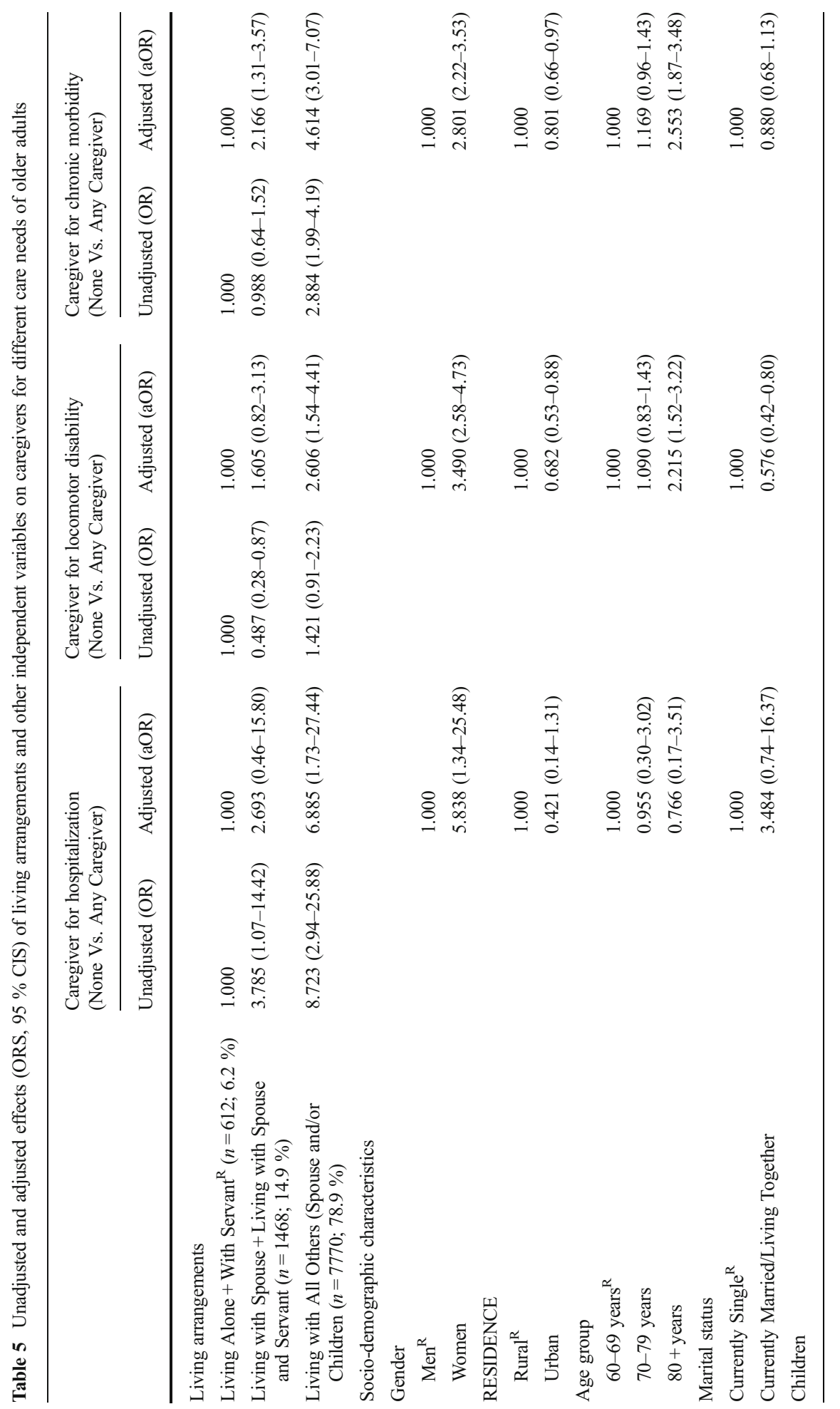




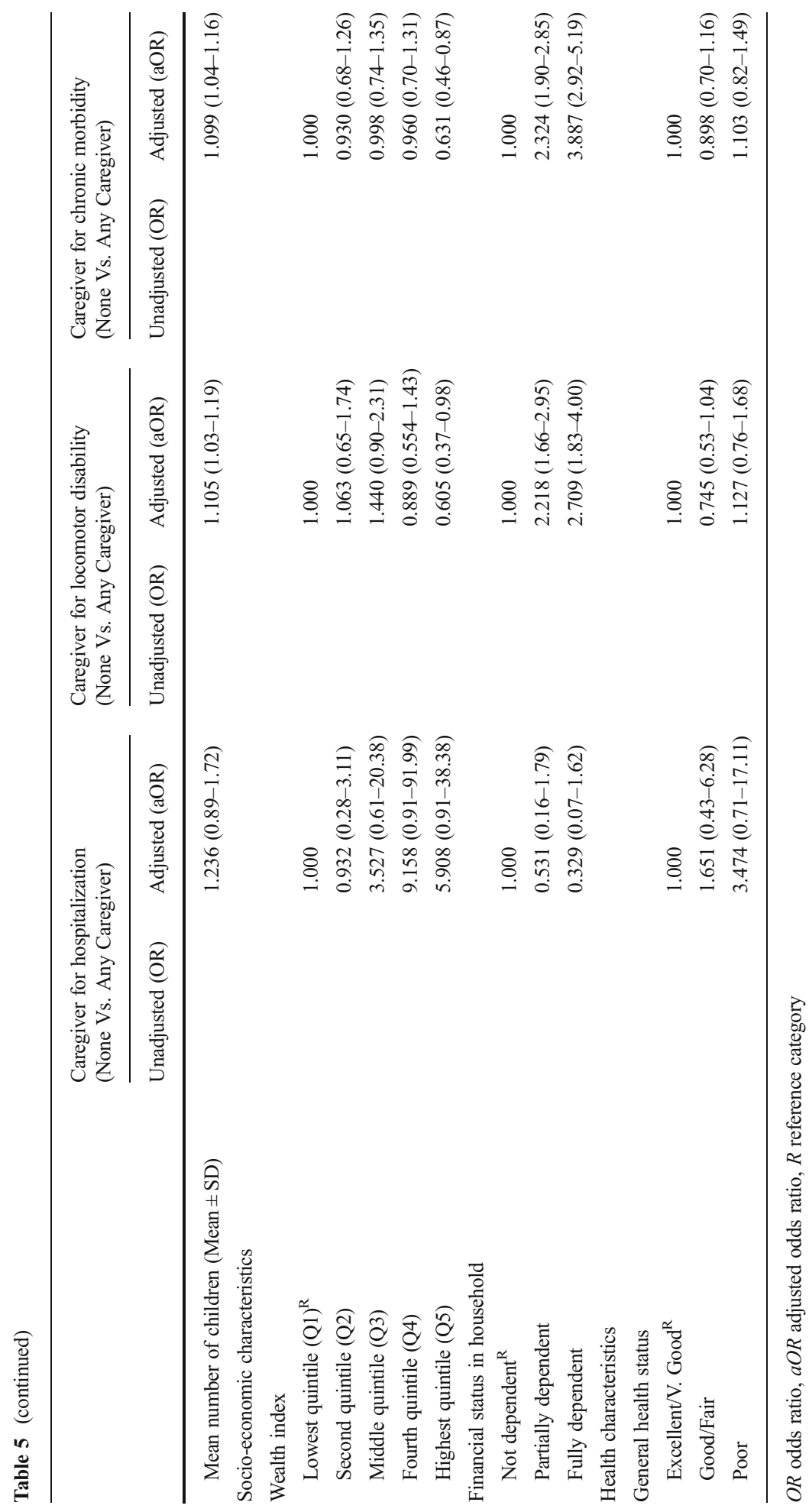


characteristics, the study has importantly aimed to explore how the care needs of older adults and care provision to them differ by living arrangements for different care-requiring situations. The care-requiring situations considered here include acute sickness, sickness requiring hospitalization, chronic morbidity, functional disability represented by ADL and IADL difficulties, and locomotor disability.

The paper has aimed to answer five dimensions: (1) whether care needs are different for older adults across socio-demographic, socio-economic and health characteristics and by their living arrangements, (2) whether caregiving to older adults varied for different care needs by living arrangements, (3) to estimate the contribution of spouse, family members and non-family members (relative/friend) in care provision to older adults for different care needs by their living arrangements, (4) to demonstrate effects of living arrangements on caregiving and (5) to identify care gaps that the analysis brings forth.

From the results, living arrangements were significantly associated with health and functional status as well as caregiving patterns. This study found that while living alone did not substantially disadvantage older adults with respect to ADL limitations or acute sickness or hospitalization, it was significantly associated with a higher proportion of locomotor disability, chronic morbidity and higher IADL limitations. Zyzanski et al. 1989, had reported that older adults living with children had worse outcomes as compared to those who lived alone while there were other studies who found the converse, i.e., that living alone had disadvantaged individuals with regards to functional health (Macran et al. 1996; Denton and Walters 1999) and other measures of health.

While our findings conform to those from prior research on the contribution of family, especially children and spouse apart from other family members towards general care provision for older adults in India (Cicirelli 1990; Gupta and Pillai 2002); they bring newer insights into care provision for specific care needs of older adults by their living arrangement. The contribution of relatives, friends and non-family contacts which was hitherto assumed to be less and not quantified is seen to be emerging through this sample. Non-family contribution to caregiving is accounting for around $8-10 \%$ of the caregiving contribution across older adults' care requirements.

This study also found that co-residence, which allows the pooling of resources and supports individual family members in times of need (Husain and Ghosh 2011), is very much existent in India and plays a crucial role in the care and support to older adults. Further, co-residence of older adults with children and significant others is likely to assure continued care and support, although smaller contributions from relatives, friends and others outside the family or household are emerging. Presence of the spouse has ensured care availability to the older adult requiring care. Messeri et al. (1993) had earlier found that an available spouse usually provides all the much needed care to an older adult requiring care; it is only when the spouse is absent that available children are likely to provide care more than other relatives or friends. The 'any family' member category accounts for the highest proportion among caregivers to older adults, rightly so since it includes children, sons-in-law/daughters-in-law and grand-children. This typically exemplifies the intergenerational bonding and co-residence of parents with their children and grandchildren in India which ensures care availability to the older adults. It also highlights the care gaps that could arise when older adults begin to live alone and brings to the fore the self-dependence that older adults living alone resort to even in failing health and functional status. 
The study also found that older adults who lived alone had a better disability status as compared to those who lived with children and others. What this probably indicates is that living alone is in part influenced by the ability to independently handle routine tasks; however, in the Indian situation this must be read cautiously since the choice to live alone is often not the decision of the older adult and could be the result of being vulnerable and socially rejected by family and others. On the one hand, living alone might mean financial ability to live independently, while on the other hand it might also point to social isolation and social deprivation from one's family (Tohme et al. 2011) which might be closer to reality in the Indian context given the low financial independence of older adults. Kodoth and Rajan (2008) had found that it was likely that older adults who lived alone were either without bequeathable assets and thus had a relatively higher likelihood of residence in old-age homes, living alone, and being looked after by relations other than their children when widowed.

One peculiarity in the findings was that even though older adults lived alone, the proportion of care and support they received from their family was still high. It is difficult to say whether older adults actually received all this care when living alone or whether they chose not to report care deficit from the family as it is a taboo to reveal such issues in India. The findings however indicate to us that there was familial help available to older adults in care-requiring situations even though they lived alone. Whether this unearths a relatively recent trend in living arrangements, appropriately referred to as "living apart but together", wherein joint family co-residence is discontinued but strong social support is immediately available, particularly in times of health crises (Sokolovsky 2001) needs to be further explored.

Despite the relevance of these findings, we recognize the limitations in the study. This being a cross-sectional study is unable to capture the nuances that caregiving and care-receiving entail for the older adult and the longitudinal changes that arise with advancing age. The cross-sectional nature of the data also brings forth the issue of endogeneity that likely exists between caregiving and living arrangements. We could not address other parameters of older adult life such as life satisfaction, emotional care, communication needs and holistic ageing in this study. The health of both spouses was also not available in the data which would have been vital information since the nature and availability of spousal help depends on the health status of both partners (Feld et al. 2004). Another important dimension which could not be answered through this analysis is the recognition that as life expectancy of older adults increase and they remain healthy at advanced ages, older men and women are also able to contribute to the wellbeing of their families and communities too (Hughes et al. 2007; Verbugge and Chan 2008; Silverstein et al. 2002). This reciprocal nature of caregiving and support is often less recognized as societies begin to age. This biased thought process has resulted in older adults being labelled as a worrisome burden in rapidly evolving societies such as in India. It would be interesting to qualitatively explore who the actual caregivers among the family and non-family sources are and how the exchange of care between older adults and their significant others ensues in the household setting (Dowd 1980).

In conclusion, this study advances knowledge about caregiving to older adults in India for health, functional and disability needs by their living arrangements. It reinforces that informal care to older adults is the mainstay in the Indian context and brings forth the care gaps that exist for older adults living alone. It also acknowledges that non-family sources of caregiving are steadily becoming visible, especially for those 
older adults living alone or away from their spouse and children. Although familybased caregiving is still the norm for older adults, the fact that there is a steady increase in older adults living alone or living away from the traditional joint family is going to challenge care availability and provision to them. Increasing nuclearization of families and migration of children away from the traditional multi-generational households are important areas of concern when we think of the care needs of older adults. Significant directions can be found for research and policy from this study on how living arrangements of older adults dictate care provision to them and how older adults might continue to benefit from family-based caregiving as hitherto formal caregiving and assisted living is near negligible in the Indian context. A deeper understanding of the process by which families and who within the family living arrangement comes to assume the responsibility of caring for the older adult is very essential for planning, designing and evaluation of older adult support policies. As the Indian Government encourages family-based caregiving and co-residence for the benefit of the elderly, initiatives such as tax incentives for a co-residing adult child might be a model for ensuring care availability for older adults within the household (Government of India (GOI) 2007). Care gaps for older adults living alone have come to the fore and concerted efforts are necessary to ensure that those older adults who have substantial care needs are not disadvantaged on account of their living arrangement.

Acknowledgments The authors would like to thank Daniel J. Herbers, PhD Researcher, Faculty of Spatial Sciences, University of Groningen, for valuable comments and suggestions received on an earlier version of this paper.

\section{Compliance with Ethical Standards}

Conflict of Interest The authors declare no conflict of interest.

Informed Consent Informed consent was obtained from all individual participants included in the study.

Ethical Treatment of Experimental Subjects (Animal and Human) Disclosure of potential conflicts of interest has been provided. This study was based on a large dataset that is publicly available on population ageing in India conducted by the UNFPA in India with ethical standards being complied with including informed consent obtained from participants.

Funding This paper was written within the Indian-European Research Networking Grant: Ageing and WellBeing in a Globalising World, funded by NWO-ESRC-ICSSR (Project Number: 465-11-009). The participating institutions include the Institute for Social and Economic Change, Bangalore, India; Center for Development Studies, Trivandrum, India; Population Research Centre, University of Groningen, The Netherlands and the University of Southampton, United Kingdom.

Open Access This article is distributed under the terms of the Creative Commons Attribution 4.0 International License (http://creativecommons.org/licenses/by/4.0/), which permits unrestricted use, distribution, and reproduction in any medium, provided you give appropriate credit to the original author(s) and the source, provide a link to the Creative Commons license, and indicate if changes were made.

\section{References}

Agarwal, S. (2012). Effect of living arrangement on the health status of elderly in India. Asian Population Studies, 8(1), 87-101. 
Agree, E. M., Biddlecom, A.E. \& Valente, T.W. (1999). Multi-generational exchanges in Taiwan and the Philippines: a social network approach. Paper presented at the 1999 annual meeting of the Population Association of America.

Alam, M. (2006). Ageing in India: socio-economic and health dimensions. New Delhi: Academic Foundation.

Albert, S. M. (2004). Public health and aging, an introduction to maximizing function and well-being. New York: Springer Publishing Company, Inc.

Arokiasamy, P., Bloom, D., Lee, J., Feeney, K., \& Ozolins, M. (2010). Longitudinal Aging Study in India (LASI): vision, design, implementation, and some early results, PGDA Working Paper No. 82. http:// www.hsph.harvard.edu/pgda/working.htm. Accessed 16 Aug 2015.

Bloom, D. E., Mahal, A., Rosenberg, L., \& Sevilla, J. (2010). Economic security arrangements in the context of population ageing in India. International Social Security Review, 63(3-4), 59-89.

Building Knowledge Base on Population Ageing in India (BKPAI) Survey Data. (2011). Available: http:// www.isec.ac.in/prc-AginginIndia-Data-Release.html. Accessed 16 Aug 2015.

Census of India, (2011). Office of the registrar general and census commissioner, India. Ministry of Home Affairs, Government of India. Available at: http://www.censusindia.gov.in/2011census/population enumeration.aspx. Accessed 16 Aug 2015.

Chan, A. (1997). An overview of the living arrangements and social support exchanges of older Singaporeans. Asia-Pacific Population Journal, 12, 35-50.

Cicirelli, V. G. (1990). Family support in relation to health problems of the elderly. In T. H. Brubaker (Ed.), Family relationship in later life (pp. 212-228). Newbury Park, CA: Sage.

Denton, M., \& Walters, V. (1999). Gender differences in structural and behavioral determinants of health: an analysis of the social production of health. Social Science and Medicine, 48, 1221-1235.

Deshingkar, P. \& Akter, S. (2009). Migration and human development in India. Human Development Reports. United Nations Development Programme.

Devi, P. B., \& Indira, R. N. (2007). Older persons, and caregiver burden and satisfaction in rural family context. Indian Journal of Gerontology, 21(2), 216-232.

Devi, N. P., \& Murugesan, P. T. (2006). Institutional care for the elderly. Journal of the Indian Academy of Geriatrics, 2(1), 15-20.

Dowd, J. J. (1980). Exchange rates and old people. Journal of Gerontology, 35, 596-602.

Feld, S., Dunkle, R. E., \& Schroepfer, T. (2004). Race/ethnicity and marital status in IADL caregiver networks. Research on Aging, 26(5), 531-558.

Fried, L., \& Guralnik, J. (1997). Disability in older adults: evidence regarding significance, aetiology, and risk. Journal of the American Geriatrics Society, 45, 92-100.

Government of India (GOI). (2007). Maintenance and welfare of parents and senior citizens Act, 2007, in Gazette of India (Extraordinary). http://socialjustice.nic.in/oldageact.php?format=largeprint>. Accessed 16 Aug 2015.

Gupta, R., \& Pillai, V. (2002). Cultural influences on perceptions of caregiver burden among Asian Indians and Pakistanis. The Southwest Journal on Aging, 17(1/2), 65-74.

Gupta, I., Sankar, D. (2002) Health of the elderly in india: a multivariate analysis. New Delhi: Institute of Economic Growth. Discussion Paper 46. Available: http://iegindia.org/dis_ind_46.pdf. Accessed 16 Aug 2015.

Hughes, M. E., Waite, L. J., LaPierre, T. A., \& Luo, Y. (2007). All in the family: The impact of caring for grandchildren on grandparents' health. The Journals of Gerontology Series B: Psychological Sciences and Social Sciences, 62(2), 108-119.

Husain, Z., \& Ghosh, S. (2011). Is health status of elderly worsening in India? A comparison of successive rounds of national sample survey data. Journal of Biosocial Science, 43(02), 211.

Ingle, G. K., \& Nath, A. (2008). Geriatric health in India: Concerns and solutions. Indian Journal of Community Medicine, 33, 214-218.

Knodel, J., \& Chayavon, N. (1997). Family support and living arrangements of Thai elderly. Asia-Pacific Population Journal, 12, 1-17.

Kodoth, P., \& Rajan, S. I. (2008). Property and assets as economic security. In S. I. Rajan, C. Risseeuw, \& M. Perera (Eds.), Institutional provisions and care for the aged: perspectives from Asia and Europe (pp. 83114). New Delhi: Anthem Press.

Krishnaswamy, B., Sein, U. T., Munodawafa, D., Varghese, C., Venkataraman, K., \& Anand, L. (2008). Ageing in India. Ageing International, 32(4), 258-268.

Lamb, S. (1999). Aging, gender and widowhood: perspectives from rural west Bengal. Contributions to Indian Sociology, 33(3), 541-570.

Lee, R. (2003). The demographic transition: three centuries of fundamental change. Journal of Economic Perspectives, 17(4), 167-190. 
Levkoff, S. E., Levy, B. R., \& Weitzman, P. F. (1999). The role of religion and ethnicity in the help seeking of family caregivers of elders with Alzheimer's disease and related disorders. Journal of Cross-Cultural Gerontology, 14, 335-356.

Lloyd-Sherlock, P. (2010). Population ageing and international development: from generalisation to evidence. Portland, OR: Policy. Available: http://hollis.harvard.edu/?itemid=\%7Clibrary $/ \mathrm{m} / \mathrm{aleph} \%$ 7C012264681. Accessed 16 Aug 2015.

Macran, S., Clarke, L., \& Joshi, H. (1996). Women's health: dimensions and differentials. Social Science and Medicine, 42, 1203-1216.

Messeri, P., Silverstein, M., \& Litwak, E. (1993). Choosing optimal support groups: a review and reformulation. Journal of Health and Social Behavior, 24, 122-137.

NSSO, 60th Round. (2004). Ministry of statistics and programme implementation. http://mospi.nic.in/Mospi New/site/inner.aspx?status=4\&menu_id=53. Accessed 16 Aug 2015.

Panigrahi, A. (2009). Determinants of living arrangements of elderly in orissa: an analysis. ISEC Working Paper Series (228). Available: http://www.isec.ac.in/WP\%20228\%20-\%20Akshaya\%20Kumar\% 20Panigrahi.pdf. Accessed 16 Aug 2015.

Pope, A. M., \& Tarlov, A. R. (1991). Disability in America. Toward a national agenda for prevention. Washington, DC: National Academy Press.

Prakash, I. J. (1999). Adult Women and the aging process. Ageing and Society, X(III and IV).

Rajan, S. I., \& Kumar, S. (2003). Living arrangements among Indian elderly: new evidence from national family health survey. Economic and Political Weekly, 38(1), 75-80.

Rajan, R. G., \& Prasad, E. S. (2008). A pragmatic approach to capital account liberalization. Journal of Economic Perspectives, 22(3), 149-172.

Report on the Status of Elderly in Select States of India. (2011). Building Knowledge Base on Ageing in India (BKPAI): Report. Available: http://www.isec.ac.in/AgeingReport_28Nov2012_LowRes-1.pdf. Accessed 16 Aug 2015.

Rutstein, S. (1999). Wealth versus expenditure: comparison between the DHS wealth index and household expenditure in four departments of Guatemala. Calverton, Maryland: DHS Comparative Reports. ORC Macro. https://dhsprogram.com/pubs/pdf/CR6/CR6.pdf. Accessed 16 Aug 2015.

Sereny, M. (2011). Living arrangements of older adults in China: the interplay among preferences, realities, and health. Research on Aging, 2, 172-204.

Silverstein, M., Conroy, S. J., Wang, H., Giarrusso, R., \& Bengtson, V. L. (2002). Reciprocity in parent-child relations over the adult life course. The Journals of Gerontology Series B: Psychological Sciences and Social Sciences, 57(1), S3-S13.

Situation Analysis of the Elderly in India (2011). Ministry of Statistics and Programme Implementation (MOSPI), Government of India. http://mospi.nic.in/mospi_new/upload/elderly_in_india.pdf. Accessed 16 Aug 2015.

Sokolovsky, J. (2001). Living arrangements of older persons and family support in less developed countries. Population Bulletin of the United Nations Spl. Issue (Living arrangements of older persons-Critical issues and policy responses), 42/43, 162-192.

Spillman, B., \& Pezzin, L. E. (2000). Potential and active family caregivers: changing networks and the 'Sandwich' generation. Milbank Quarterly, 78(3), 347-374.

Sudha, S., Suchindran, C., Mutran, E. J., Rajan, S. I., \& Sarma, P. S. (2006). Marital status, family ties and self-rated health among elders in South India. Journal of Cross-Cultural Gerontology, 21, 3-4.

Tohme, R., Yount, K., Yassine, S., Shideed, O., \& Sibai, A. (2011). Socioeconomic resources and living arrangements of older adults in Lebanon: who chooses to live alone? Ageing and Society, 31(01), 1 .

United Nations. (2005). Living arrangements of older persons around the world. Department of Economic and Social Affairs. Population Division. United Nations: New York, NY. http://www.un.org/esa/ population/publications/livingarrangement/es_english.pdf. Accessed 16 Aug 2015.

Verbugge, L. M., \& Chan, A. (2008). Giving help in return: family reciprocity by older Singaporeans. Ageing and Society, 28(01), 5.

Visaria, P. (1999). Demographics of ageing in India: an abstract (draft). New Delhi, University of Delhi Institute of Economic Growth. http://www.epw.in/special-articles/demographics-ageing-india.html. Accessed 16 Aug 2015.

World Health Organization (WHO). (2002). Reducing stigma and discrimination against older people with mental disorders. Geneva, World Health Organization and World Psychiatric Association. Available: http://whqlibdoc.who.int/hq/2002/WHO_MSD_MBD_02.3.pdf. Accessed 16 Aug 2015. 
World Health Organization. (WHO). (1980). International classification of impairments, disabilities, and handicaps. Geneva: World Health Organization. Available: http://whqlibdoc.who.int/publications/1980/ 9241541261_eng.pdf. Accessed 16 Aug 2015.

Zyzanski, S. J., Medalie, J. H., Ford, A. B., \& Grava-Gubins, I. (1989). Living arrangements and well-being of the elderly. Family Medicine, 21, 199-205.

Dr. Allen P. Ugargol is a PhD Researcher in Population Studies from the University of Groningen (RUG), Groningen, The Netherlands and the Institute for Social and Economic Change (ISEC), Bangalore, India. His research interests include ageing, population studies, public health, health economics, and health informatics.

Prof. Inge Hutter is Professor of Demography at the Faculty of Spatial Sciences, University of Groningen and Rector of the International Institute of Social Studies (ISS) at The Hague. Her research interests encompass demography, anthropology and health policy.

Prof. K. S. James is Professor of Demography at the Population Research Centre (PRC), Institute for Social and Economic Change (ISEC). His research interests include formal demography, population and development, ageing issues, mortality and health.

Dr. Ajay Bailey is Assistant Professor of Population Studies at the Faculty of Spatial Sciences, University of Groningen, The Netherlands. His research interests include demography, migration studies, anthropology, ageing and health services. 